San Jose State University

SJSU ScholarWorks

Master's Theses

Master's Theses and Graduate Research

2004

\title{
Client satisfaction, employment status, and treatment outcome among drug abusers
}

Rula Nasser-Mazzawi

San Jose State University

Follow this and additional works at: https://scholarworks.sjsu.edu/etd_theses

\section{Recommended Citation}

Nasser-Mazzawi, Rula, "Client satisfaction, employment status, and treatment outcome among drug abusers" (2004). Master's Theses. 2551.

DOI: https://doi.org/10.31979/etd.eg3w-d239

https://scholarworks.sjsu.edu/etd_theses/2551

This Thesis is brought to you for free and open access by the Master's Theses and Graduate Research at SJSU ScholarWorks. It has been accepted for inclusion in Master's Theses by an authorized administrator of SJSU ScholarWorks. For more information, please contact scholarworks@sjsu.edu. 


\title{
CLIENT SATTSFACTION, EMPLOYMENT STATUS, AND TREATMENT OUTCOME AMONG DRUG ABUSERS
}

\author{
A Thesis \\ Presented to \\ The Faculty of the Department of Psychology
}

San Jose State University

In Partial Fulfillment of the Requirements for the Degree

Master of Science

By

Rula Nasser-Mazzawi

May 2004 
UMI Number: 1420433

\author{
Copyright 2004 by \\ Nasser-Mazzawi, Rula
}

All rights reserved.

\title{
INFORMATION TO USERS
}

The quality of this reproduction is dependent upon the quality of the copy submitted. Broken or indistinct print, colored or poor quality illustrations and photographs, print bleed-through, substandard margins, and improper alignment can adversely affect reproduction.

In the unlikely event that the author did not send a complete manuscript and there are missing pages, these will be noted. Also, if unauthorized copyright material had to be removed, a note will indicate the deletion.

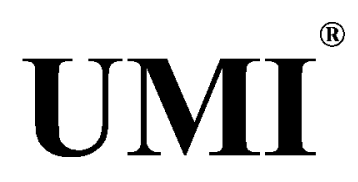

UMI Microform 1420433

Copyright 2004 by ProQuest Information and Learning Company. All rights reserved. This microform edition is protected against unauthorized copying under Title 17, United States Code.

\author{
ProQuest Information and Learning Company \\ 300 North Zeeb Road \\ P.O. Box 1346 \\ Ann Arbor, MI 48106-1346
}


(C) 2004

Rula Nasser-Mazzawi

ALL RIGHTS RESERVED 

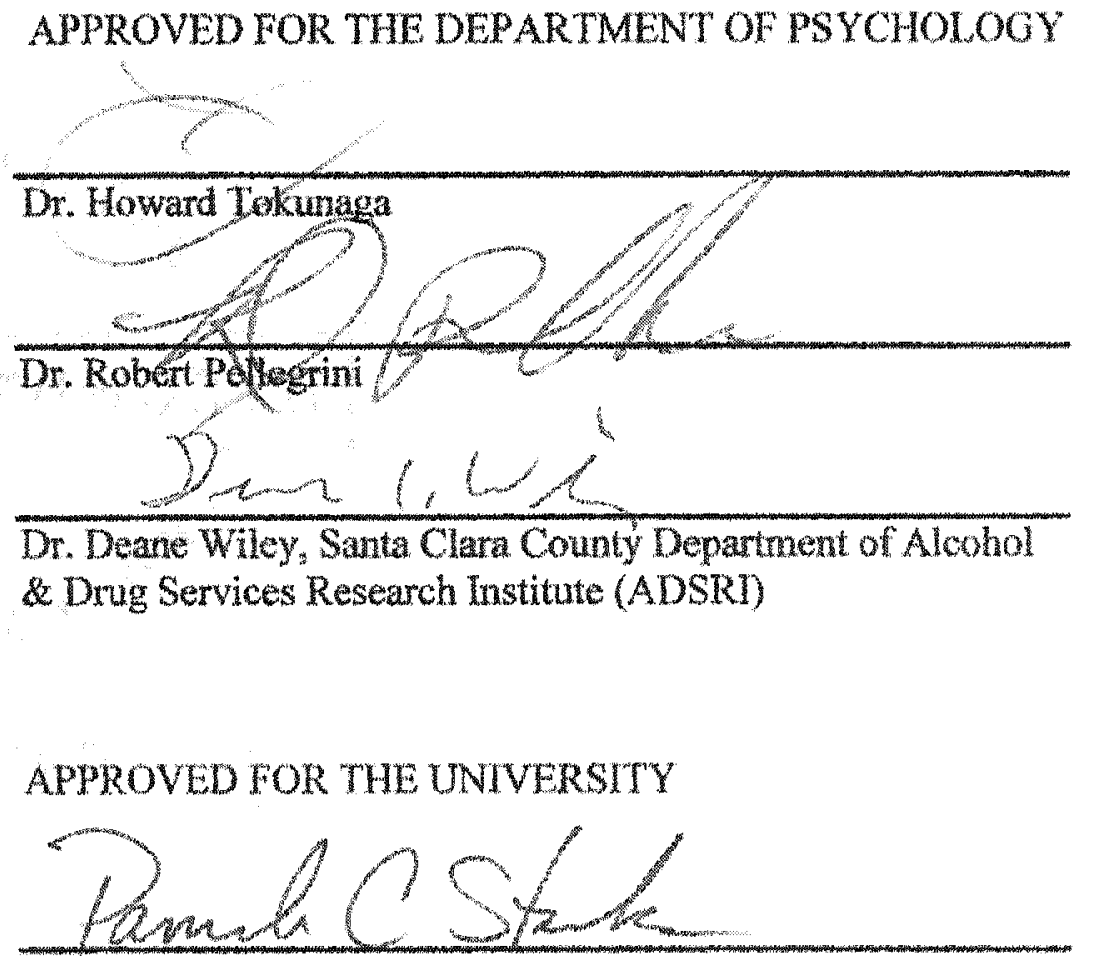


\begin{abstract}
CLIENT SATISFACTION, BMPLOYMENT STATUS, AND TREATMENT OUTCOME AMONG DRUG ABUSERS
\end{abstract}

\begin{abstract}
By Rula Nasser-Mazzawi
This thesis addresses the relationship between consumer satisfaction ratings, change in status of employment between admission and discharge from treatment; and the treatment outcome, among outpatient alcohol and drug addicted clients. The study is an analysis of data collected for the substance abuse treatment program, Santa Clara

County, California.
\end{abstract}

The results of the current study suggest that while there is a significant positive effect of client satisfaction on the discharge status, there was no such effect on the frequency of drug use. In addition, we found that clients, who improve their employment status (get a job), have better discharge status and tend to use drugs less frequently, compared to clients who lose their jobs. Theoretical and practical implications of these results were discussed; in addition, suggestions for future research were presented. 


\section{Acknowledgments}

I would like to express my gratitude to my advisor, Dr. Howard Tokunaga, whose expertise, knowledge, and skills added considerably to my graduate experience. 1 appreciate his encouragement, insight, and direction throughout my work on this thesis. I would also like to thank. Dr. Robert Pellegrini for his assistance as my second reader.

Special thanks go to my colleagues at Santa Clara County, Department of Alcohol and Drug Services Research Institute (ADSRI) for providing the support and resources which enabled me to pursue this research. Special thanks to Dr. Deane Wiley for his valuable input, and his continuous guidance and encouragement.

My most heartfelt acknowledgment goes to my husband and best friend Jamil for his support and understanding; without his love and companionship I would not have finished my degree. He has my everlasting love.

I wish to thank my daughters Sama and Juna; they are the source of energy and joy in my life. Finally, my very special thanks to my parents, especially my mother, their love and influence will always remain with me. 
Page number

Introduction 1

Treatment Outcomes 2

Predictors of Treatment Outcome $\quad 2$

Evaluation of the Literature 6

Purpose of the Present Study 9

$\begin{array}{ll}\text { Method } & 11\end{array}$

$\begin{array}{ll}\text { Participants } & 11\end{array}$

$\begin{array}{ll}\text { Measures } & 12\end{array}$

$\begin{array}{ll}\text { Procedure } & 16\end{array}$

$\begin{array}{ll}\text { Results } & 17\end{array}$

$\begin{array}{ll}\text { Descriptive Statistics } & 17\end{array}$

$\begin{array}{ll}\text { Chi Square Analyses } & 17\end{array}$

$\begin{array}{ll}\text { Discussion } & 25\end{array}$

Relationship Between Consumer Satisfaction and the Treatment Outcome 25

Relationship Between Status of Employment and Treatment Outcome 27

$\begin{array}{lr}\text { Implications } & 28\end{array}$

$\begin{array}{lr}\text { Strengths and Weaknesses } & 28\end{array}$ 


\section{List of Tables}

Table

Page number

Table 1. Frequencies and percentages of demographic variables

Table 2. Numbers and percentages of each category for client satisfaction

and status of discharge

Table 3. Numbers and percentages in each category for status of employment and status of discharge

Table 4. Numbers and percentages in each category for status of employment and frequency of drug use 


\section{List of Figures}

Figure

Page number

Figure1. Percentages for discharge status by client satisfaction score (CSQ) 20

Figure 2. Percentages for discharge status by change in status of employment 22

Figure 3. Percentages for change in frequency of drug use by change

in status of employment. 


\section{NTRODUCTION}

Substance abuse and dependence are characterized by prolonged and regular substance use that is associated not only with a variety of psychological, interpersonal, academic, family, and legal problems, but also with continued use despite the associated problems (APA, 1994). Substance abuse treatment is a programmatic intervention that primarily aims to reduce patients' use of drugs (Rapp, Siegal, Li \& Saha; 1998). Many studies in the past few decades have shown the effectiveness of substance abuse treatment as measured by outcomes such as drug use, criminality, and employment (Zarkin et al, 2002). However, they have not addressed the effects of employment status on the treatment outcome. This study will focus on the relationship between client satisfaction from the treatment and employment status, on treatment outcome among outpatient alcohol and drug client.

Generally, there are two basic treatment goals: specific treatment of the addiction itself and abstinence, the state of being without a drug on which one is dependent, or at least reduction of substance use. However, treatment of the causes of addiction through the reduction of signs and symptoms of the consequences of substance abuse, resolution. of medical, psychiatric, and social problems, and a change in attitude about substanceusing behavior, are also important treatment goals that help in attaining long-tem results (Howard, 2003). 
Relapse is the problem of falling back into substance abuse after an apparent recovery (Webster, 2001). The high rate of relapse (40\%-60\%) of drug abuse treatment patients to drug use within one year following treatment discharge reveals the need for multiple treatment episodes in many drug addicted individuals, especially since most treatments seem to be brief by design. Thus, treatment programs should aim not only to initiate abstinence, but also to sustain it over greater spans of time (Silverman et al., 2002).

\section{Treatment Outcomes}

Different studies defined treatment outcome in terms of different dependent variables. Dobkin, Luc, Katia, \& Wendy (1998), Zarkin et al. (2002) and Messina, Nemes, Wish \& Wraight (2001) used treatment completion as a measure for treatment outcome. Completion status was identified by the program at the time of the discharge interview, if the reason for a patient's discharge was "completed planned treatment" then the patient was classified as a treatment completer, otherwise he was a treatment non completer. Other studies used other variables to measure treatment outcome (Rapp et al., 1998; Siegal \& Rapp, 2002; Hoffman, Caudill, Koman, Luckey, Flynn, \& Mayo, 1996).

\section{Predictors of Treatment Outcome}

Client satisfaction. An important variable in predicting treatment success is the clients' satisfaction with the treatment. Client satisfaction refers to clients assessment regarding their perceptions of how well services were based on their needs (Sanders, Trihn, Sherman, and Banks; 1998). According to Ware and Davies (1983) client 
satisfaction is the definitive outcome to foresee the treatment success.

An important function of the client satisfaction assessments is that they focus on understanding the client's perceptions of the care they receive. In their research Conners \& Franklin (2000) assessed client satisfaction through the use of focus groups at a comprehensive drug treatment program for women and their children. The results showed that participants were able to identify which services were most important to their recovery, unmet needs, and steps that can be taken to further improve the treatment program.

The use of consumer satisfaction questionnaires has increased dramatically over the past 10 years in the general health care services including the area of addictions treatment (Williams, 1994). In spite of this increased emphasis, the literature regarding client satisfaction is still limited. One constant finding among these studies is the finding that reported levels of satisfaction are almost always high regardless of treatment modality (Conners \& Franklin, 2000). However, the current literature contradicts regarding almost every other treatment aspect.

For example, in a study by Holcomb et al. (1997) they found that client satisfaction with treatment was found to be positively related to treatment gains in quality of life, symptoms, and level of functioning. Similarly, in a study by Chan et. al. (1997) they found a correlation between client satisfaction and treatment retention as well as some treatment outcomes. However, in a study by McLellan \& Hunkeler (1998), levels of client satisfaction were found not to be related to performance indicators of the treatment 
outcome.

In summary, though the use of client satisfaction questionnaires is fairly rocent (Willams, 1994), it has advantages. The most important is taking into account the clients' perspectives over the treatment plans that they go through. Another important point is the fact that it can identify aspects of the plan and treatment that are improvement priorities (Shaul, Eisen, Stringfellow, Clarridge, Hermann, Nelson, Anderson, Kubrin, Leff, \& Cleary, 2001).

Employment status. Employment status is commonly used as a sign of stability in recovery for substance abuse treatment and research (Laudet, 2002). Luchansky, Brown, Longhi, Stark \& Krupski (2000) assert that although the main focus of the treatment is abstinence, other factors such as employment functions as an indicator of social rehabilitation (Metzger \& Platt, 1990) since it helps clients to integrate with the larger society, and allows for economic self-sufficiency. In addition, employment protects clients against relapse (Catalano et al., 1988), and is associated with a lot of positive mental and physical outcomes. (Braunstein et al., 1983; Hser, Hoffman, Grella \& Anglin; 2001).

According to Bray, Zarkin, Dennis \& French (2000), many of the consequences of alcohol and drug disorders are likely to be associated with unemployment. Their study suggests that, for both men and women, substance abuse with symptoms of dependence is associated with lower employment and higher unemployment. For men, substance abuse with symptoms of dependence is also associated with fewer hours of work. Similarly, 
Hser, Hoffiman, Grella \& Anglin (2001) found that heroin-users consistently reported lower rates of employment than did abstinent past heroin users.

What is the relationship between employment and drug treatment? Rapp, Siegal \& Saha (1998) examined employment at admission as predictor of treatment outcome. They found that those who did not hold a steady job at intake were more likely to stay longer in post-treatment aftercare than others.

Luchansky, et. al. (2000) found that clients who received vocational services while completing their treatment earned more than those who completed treatment only. Those who received vocational services earned significantly more after receiving these services than they did before (Luchansky et al., 2000).

In a study of the relationship between drug use and post-treatment employment, Sterling et al., (2001) found that independent of patient functioning at intake, persons working reported significantly fewer days of cocaine use in the month before follow-up than those not employed. A significantly smaller percentage of persons working gave urine samples that were cocaine positive than did those who were not working. In addition, patients employed at follow-up were less likely to report any period of incarceration in the time between treatment end and follow-up contact. Overall, they were functioning better with regard to social and drug use parameters than those who were not employed (Siegal \& Rapp, 2002).

Another evidence for the relationship between employment and drug use comes from research by Silverman et al. (2002) that focused on an employment-based intervention 
called Therapeutic Workplace, in which participants can work and earn a salary but only as long as they remain drug abstinent. The intervention has two phases. Phase 1 , participants who lack job skills receive needed training. Skilled participants progress to phase 2, during which they are hired to perform real jobs. Throughout both phases of the treatment, the salary-based abstinence reinforcement was maintained. This Selfsustaining therapeutic workplace business potentially could serve not only to initiate drug abstinence but also maintain abstinence over extended periods of time. Two studies by Silverman et al. $(2001,2002)$ showed that the Therapeutic Workplace could initiate abstinence from heroin and cocaine among pregnant women or postpartum methadone patients who had failed to achieve sustained abstinence using other treatment programs. In their recent study (2002) they found that Therapeutic Workplace participants increased drug abstinence until three years after intake.

\section{Evaluation of the Literature}

Unclear relationship between client satisfaction and treatment outcome. Client satisfaction is one factor that reflects the clients' perspective over the treatment. It focuses on the clients' perception of the treatment so no wonder it is still considered a new trend in the treatment evaluation. We also saw that from the studies mentioned above, there are contradicting results (e.g. Holcomb et al. 1997, McLellan \& Hunkelex, 1998, Chan et al., 1997) regarding the relationship between client satisfaction and the treatment outcome, and that more research in this field would be very helpful to improve the treatment programs offered for substance abuse clients. 
This relationship between client satisfaction and treatment ontcome needs to be looked at in order to further explore the extent to which treatment services should be targeted to clients' needs. Is their any relationship between clients' satisfaction from the services they receive and their treatment outcome? How important is the clients' satisfaction for the treatment success?

Employment status has not been looked at as a predictor of treatment outcome. A close look at the studies done in this field reveals that employment status during treatment has not been looked at as a predictor of treatment outcome. Sterling et al. (2001) focused mainly on post-treatment employment and the difference between those who were employed and those who were not in their drug abuse behavior and their social functioning. Although Rapp et. al. (1998) looked at employment as their predictor but they referred to status of employment at admission. All the other studies mainly used employment as their dependent variable, which they try to predict from different other variables like, treatment completion (Luchansky et al., 2000), heroin usage (Hser et al., 2001), or general substance abuse (Bray et al, 2000). Most of these studies aim at predicting the earnings of substance abusers versus the earnings of abstinent users but did not look at the social and psychological effects that employment may have on these clients.

This study focuses on the employment status, as predictor of the treatment outcome. This is important especially since a relationship like this could change the goals of the treatment programs offered in this field to put more concentration over finding a job for the clients. Instead of only trying to predict the success of the treatment from the 
employment status of the client when he starts the treatment or waiting until the treatment ends and the client gets a job to try to relate this to the treatnent outcome. This study places the clients and the counselors into a more proactive role, trying to change things in a way that makes the best use of the client's time and skills.

The studies mentioned above show that although we know a lot about the effects of substance abuse or treatment for substance abusers on earnings and status of employment, we do not know what effects does employment status have on the substance abuse treatment outcome. All the studies mentioned indicate the importance of employment on the lives of substance abusers but the main question here is, what impact does status of employment have on the treatment outcome in terms of the severity of substance abuse? If the effect of employment is that strong on the clients' lives, should treatment programs consider focusing on employment (in terms of getting the clients employed or giving them vocational training as part of their treatment program) as they do on abstinence instead of treating it as a treatment side effect?

Population does not include outpatient clients. Although outpatient drug treatment is the largest drug treatment modality (Zarkin et al., 2002) it is still underrepresented in research studies about the effectiveness of drug treatment. The above-mentioned studies have some limitations. With the exception of the study by Rapp et al. (1998), all of the other studies either focus on predictors of entering treatment (Weisner et al., 2002; Neff et al., 2000), or on very specific populations like cocaine users (Hoffman et al., 1996; Simpson et al., 2002, Siegal et al., 2002), methadone patients (Simpson, 1981; McLellan et al, 1986; Corsi et al., 2002), inpatient clients (Messina, 2001), or adolescent users 
(Dakof, 2001). None of these studies has focused on predicting treatment outcome anong adult outpatient clients, which is the targeted population in the current study.

Most studies testing predictors of treatment outcome include individuals in therapeutic communities or residential treatment only (McMahon et al., 1999 at Zarkin et al., 2002). Thus, little is known about the effects of consumer satisfaction and change in status of employment on the treatment outcome among alcohol and drugs outpatient clients.

Purpose of the Present Study

The goal of the current research is to study the relationship between consumer satisfaction ratings, employment status, and treatment outcome, defined as discharge status and frequency of drug use. Two hypotheses will be tested:

H1a: Clients who have high consumer satisfaction ratings at the end of the treatment episode will have better discharge status than clients with low consumer satisfaction ratings.

Hlb: Clients who have high consumer satisfaction ratings at the end of the treatment episode will use drugs less frequently than those who have low consumer satisfaction ratings.

H2a: Clients, who get a job or those who continue to be employed during the treatment episode, will have better discharge status compared to clients who lost their jobs or those who continued to be unemployed. 
H2b: Clients, who get a job or those who continue to be mployed during the treatment episode, will use drugs less frequently, compared to clients who lost their jobs or those who continued to be anemployed.

Eventually this study will give us better understanding of the critical elenents in the treatment of alcohol and drug addicts, and direct us in reshaping our treatment services for these clients. 
Method

\section{Participants}

The simple totaled 841 who were discharged from Santa Clara County outpatient treatment during calendar year 2000. Residential clients were excluded since they are unable to hold a job. Methadone clients were also excluded since they stay in treatment for many years. Also clients who stayed in treatment a week or less were excluded.

There are about 30 locations that provide outpatient services at Santa Clara County in several languages, English, Spanish, Vietnamese, Chinese and Tagalog. All the clients at Santa Clara County have one centralized point of entry to get into treatment through Gateway Program, which streamlines service delivery. To receive any DADS (Department of Alcohol and Drug Services) managed care alcohol or drug services, all individuals call the Gateway 800 number for information and referral services and for prescreening assessment appointments (http://www.scvmed.org/site).

The treatment personnel prescreen and refer callers to sites throughout the county for a more detailed assessment within 72 hours. These assessments match clients to the level of service they need.

Another way that clients get into outpatient modality is when they finish their stay at residential treatment or Detoxification; they could be referred into outpatient for further treatment.

Seventy percent of the sample were males. All of the participants were over 18 years of age, $70 \%$ of them between 25 and 45 years old when they started their treatment. The majority of the sample was either Hispanic (46\%) or White (38\%). Only $25 \%$ of the 
participants wert mamied at admission to treatment. The majority of them (59\%) completed at least 12 years of education (table 1 ).

Measures

Client Satisfaction Questionnaire-8 (CSQ 8; Nguyen, Atthisson \& Stegner, 1983). The CSQ-8 is a self-report questionnaire constructed to measure the general satisfaction with services received (Williams \& Wilkins, 1995). It was developed to provide a brief, standard assessment procedure suitable for use in a wide variety of service settings (Robert, Attkisson \& Mendias, 1984). The CSQ-8 is an 8-item short form of a 31 -item instrument. Altemate 18-item versions, the $\mathrm{CSQ}-18 \mathrm{~A}$ and $\mathrm{CSQ}-18 \mathrm{~B}$, are also available and have a good nomative base. Each item in the CSQ 8 is phrased as a question having a four-point anchored answer without the neutral position (Roberts \& Attkisson, 1983). Because of its good psychometric properties, for most purposes the short form CSO 8 substitutes well for the full 31 item instrument, both being designed to assess a unitary general satisfaction factor (Attkisson \& Greenfield, 1994).

The CSQ scales have been adopted in evaluation studies and clinical research across the spectrum of health and human services. The CSQ-8 is suitable for use with a variety of client populations, including Anglos, African-Americans, and Hispanics (Roberts, Attkisson \& Mendias, 1984). It has been translated into Dutch, Spanish, French, Chinese, Tagalog and Vietnamese.

Attkisson \& Zwick (1982) quoted previons studies of the CSQ 8 which found internal consistency values of 93 (Larsen, 1979), 92 (Larsen et al., 1979), and .87 (Nguyen et al. 
Table 1. Frequencies and percentages of demographic variables.

Demogr

Fernale

Male

Age

$18-24$

25-35

36.45

Over 45

Ethnicity

White

African American

Native American

Asian

Hispanic

Marital Status

Married

Currently single

Education

Under 12 Years

12 years or over
Frequency

Percent
$30 \%$

586

$70 \%$

$165 \quad 20 \%$

$314 \div 37 \%$

$272 \quad 32 \%$

$90 \quad 11 \%$

$\begin{array}{rr}318 & 38 \% \\ 39 & 5 \% \\ 9 & 1 \% \\ 85 & 10 \% \\ 390 & 46 \%\end{array}$

211

$25 \%$

$616 \quad 75 \%$ 
1981). In this study the internal reliability for the CSO was .80 . Construct validity of CSQ is enhanced by the high correlations $(r=.6$ to .8 ) found between it and other satisfaction instruments that use different strategies to measure the same construct (Attkisson \& Greenfield, 1994).

Larsen et al. (1979) indicated that responses to the CSQ-8 were not significantly related to demographic factors such as years of education, family income, marital status, amount of service, age at admission, social class or previous treatment at another facility. However, the CSQ 8 has been shown to correlate moderately with selected treatment or service variables. Larsen (1979) found that clients dropping out of the program within the first month tended to be less satisfied than those still in the program, as did those who missed a greater percentage of their scheduled appointments. Self-ratings of global improvement by clients also were correlated with CSQ 8 scores. Therapists' ratings of their satisfaction with their work with the client also were positively correlated with patient satisfaction scores, as were the estimates by the therapists of how satisfied they believed that client to be. This later finding has been interpreted as providing evidence of the concurrent validity of the CSQ-8.

In this study we differentiated between two groups on the CSQ-8. One group represents those who had an average score higher than 3.5 (high satisfaction), and the second group included those who had an average score of 3.5 or less on the CSQ-8 (low satisfaction). 
Employment status. Employment was assessed by asking the clients both at time of admission and at discharge to indicate if they are enployed or unemployed. We ended up with four different categories for the employment status: first, those who got a job, were unemployed at admission and employed at discharge. Second, those who continued to be employed, were employed at admission and at discharge. Third, those who continued to be unemployed, were unemployed at admission and at discharge. Fourth, those who lost their jobs, were employed at admission and unemployed at discharge.

Discharge status. Discharge status is the judgment of the counselor of how satisfactory the clients discharge from treatment was. Basically, the counselor was to indicate if the client completed treatment plan, left before completion, was terminated by the clinic (fee non-compliance, non-compliance with treatment plan, other administrative factors, incarcerated), or if the client was referred for further drug/alcohol treatment. We ended up with two categories for discharge status, clients that completed treatment plan were classified as satisfactorily discharged, otherwise they were classified as unsatisfactorily discharged.

Frequency of drug use. Frequency of drug use was also assessed by the counselor based on the client report and the urine analyses both at the beginning and by the end of the treatment. The counselor is to indicate if there was no past month use, $1-3$ times in past month, 1-2 times per week, 3-6 times per week, or daily use. We ended up with three different categories for frequency of drug use: First those who reduced their drug use by the end of the treatment compared to the beginning of it. Second, those who increased 
their drug use by the end of the treatment. Third, those who consumed same amount of drugs both at admission and at discharge.

\section{Procedure}

The study is an analysis of data collected for the substance abuse treatment program, Santa Clara County, Califormia, and entered into a Management Information System. The treatment counselors collected the information at the first and last sessions of the treatment. 


\section{Results}

\section{Descriptive Statistics}

In general, the mean score for the total CSQ was very high $(M=3.6$, out of 4$)$, which indicates that the clients reported high level of satisfaction. $62 \%$ were very satisfied with their treatment (total CSQ score is more than 3.5 ) while only $38 \%$ were less satisfied with the treatment (total CSQ score less than 3.5). Unless the question "To what extent has our program met your needs?", in all the other questions approximately $60 \%$ or more chose answer number 4 indicating that they are very satisfied.

The results of the status of employment show that while only $54.8 \%$ were employed at admission, $71.1 \%$ of the clients were employed at discharge. Over $40 \%$ succeeded to retain their jobs, while almost $8 \%$ lost their jobs by the end of the treatment. Over $25 \%$ got employed, while over $15 \%$ were still unemployed.

Regarding status of discharge, $66 \%$ of the clients were satisfactorily discharged while only $34 \%$ had an unsatisfactory discharge.

As for frequency of drug use at discharge, we found that by the end of treatment, more than $75 \%$ reduced their drug use, while less than $3 \%$ increased it. Roughly, this indicates that the treatment has a positive effect on drug use.

\section{Chi Square Analyses}

To test hypothesis Hla, that clients who bave high consumer satisfaction ratings at the end of the treatment episode will have better discharge status than clients with low consumer satisfaction ratings, a chi square analysis was conducted with client satisfaction 
as the independent variable and status of discharge as the dependent variable.

A significant difference was found between those who were satisfied from the treatment and those who were not, in their status of discharge $\left[\chi^{2}(1)=5.42, \mathrm{p}<05\right]$, so that among those who were more satisfied, $69 \%$ were satisfactorily discharged, while anong those who were less satisfied with their treatment, $61 \%$ had satisfactory discharge (Figure 1).

To test hypothesis Hib, that clients who have high consumer satisfaction ratings at the end of the treatment episode will use drugs less frequently than those who have low consumer satisfaction ratings, a chi square analysis was conducted with client satisfaction as the independent variable and frequency of drug use at discharge as the dependent variable. There was no significant difference between those who were satisfied from the treatment and those who were not, in the frequency of their drug use $\left[\chi^{2}(2)=4.39, p>.05\right]$. Among those who were more satisfied from the treatment $80 \%$ used drugs less at discharge than at admission and 3\% increased their drug use, while among those who were less satisfied with there treatment $73 \%$ used drugs less at discharge than at admission and $3 \%$ used drugs more than they did at admission.

Hypothesis $\mathrm{H} 2$ a clients who get a job or those who continue to be employed during the treatment episode will have better discharge status compared to clients who lost their jobs or those who continued to be unemployed, was tested by a chi square analysis with status of employment as the independent variable and status of discharge as the dependent variable. Stalus of employment was significantly related to status of discharge $\left[x^{2}(3)=43.10, p<01\right]$ so that among those who either got a new job or were 
employed at admission and contimued to be employed $75 \%$ and $72 \%$ respectively were satisfactorily discharged, while among those who lost their jobs only $39 \%$ were satisfactorily diseharged (Figure 2).

To test hypothesis $\mathrm{F} 2 \mathrm{~b}$ that clients, who get a job or those who continue to be employed during the treatment episode, will use drugs less frequently, compared to clients who lost their jobs or those who continued to be unemployed, a chi square analysis was conducted with status of employment as the independent variable and frequency of drug use as the dependent variable.

There was significant difference between those who got new jobs and those who lost their jobs in their frequency of drug use at discharge $\left[\chi^{2}(6)=12.70, p^{<.05}\right]$ so that $82 \%$ from those who got new jobs during their treatment used drugs at discharge less than at admission. While only $61 \%$ of those who lost their jobs decreased their drug use by the end of the treatment (Figure 3 ). 
Table 2. Numbers and percentages of each category for client satisfaction and status of discharge.

\author{
Client satisfaction
}

Discharge status Low client satisfaction High client satisfaction

\begin{tabular}{lcr} 
Satisfactory discharge & 195 & 361 \\
& $(61.3 \%)$ & $(69.2 \%)$ \\
Unsatisfactory discharge & 123 & 161 \\
& $(38.7 \%)$ & $(30.8 \%)$ \\
\hline Total & 318 & 522 \\
& $(100 \%)$ & $(100 \%)$
\end{tabular}

Figurel. Percentages for discharge status by client satisfaction score (CSQ).

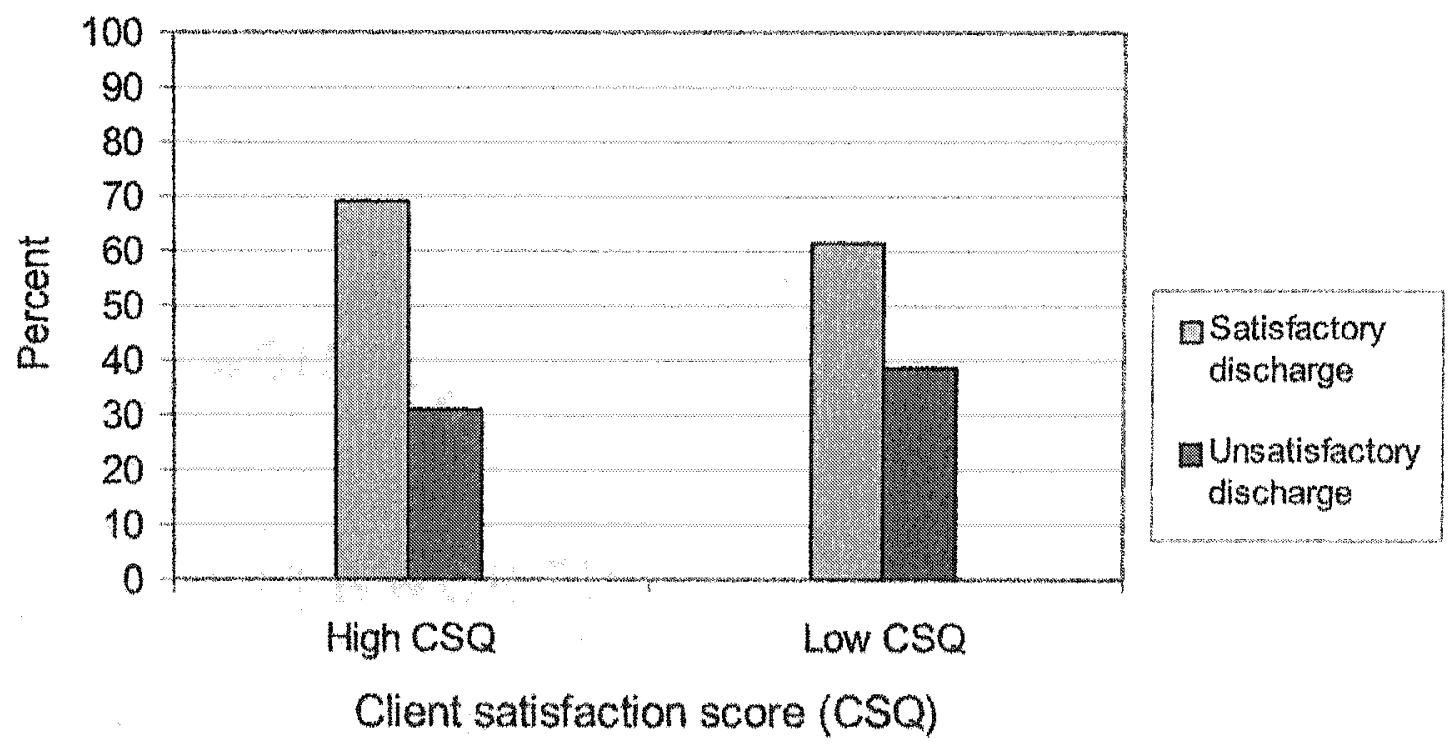


Table 3. Numbers and percentages in each category for status of employment and status of discharge.

\section{Employment status}

Continued to Continued to be

Discharge status be employed unemployed

Lost job

\begin{tabular}{lrrrc} 
Satisfactory & 161 & 274 & 73 & 21 \\
discharge & $(74.9 \%)$ & $(72.1 \%)$ & $(52.5 \%)$ & $(38.9 \%)$ \\
Unsatisfactory & 64 & 106 & 66 & 33 \\
discharge & $(25.1 \%)$ & $(27.9 \%)$ & $(47.5 \%)$ & $(61.1 \%)$ \\
\hline Total & 215 & 380 & 139 & 54 \\
& $(100 \%)$ & $(100 \%)$ & $(100 \%)$ & $(100 \%)$
\end{tabular}


Figure 2. Percentages for discharge status by change in status of employment.

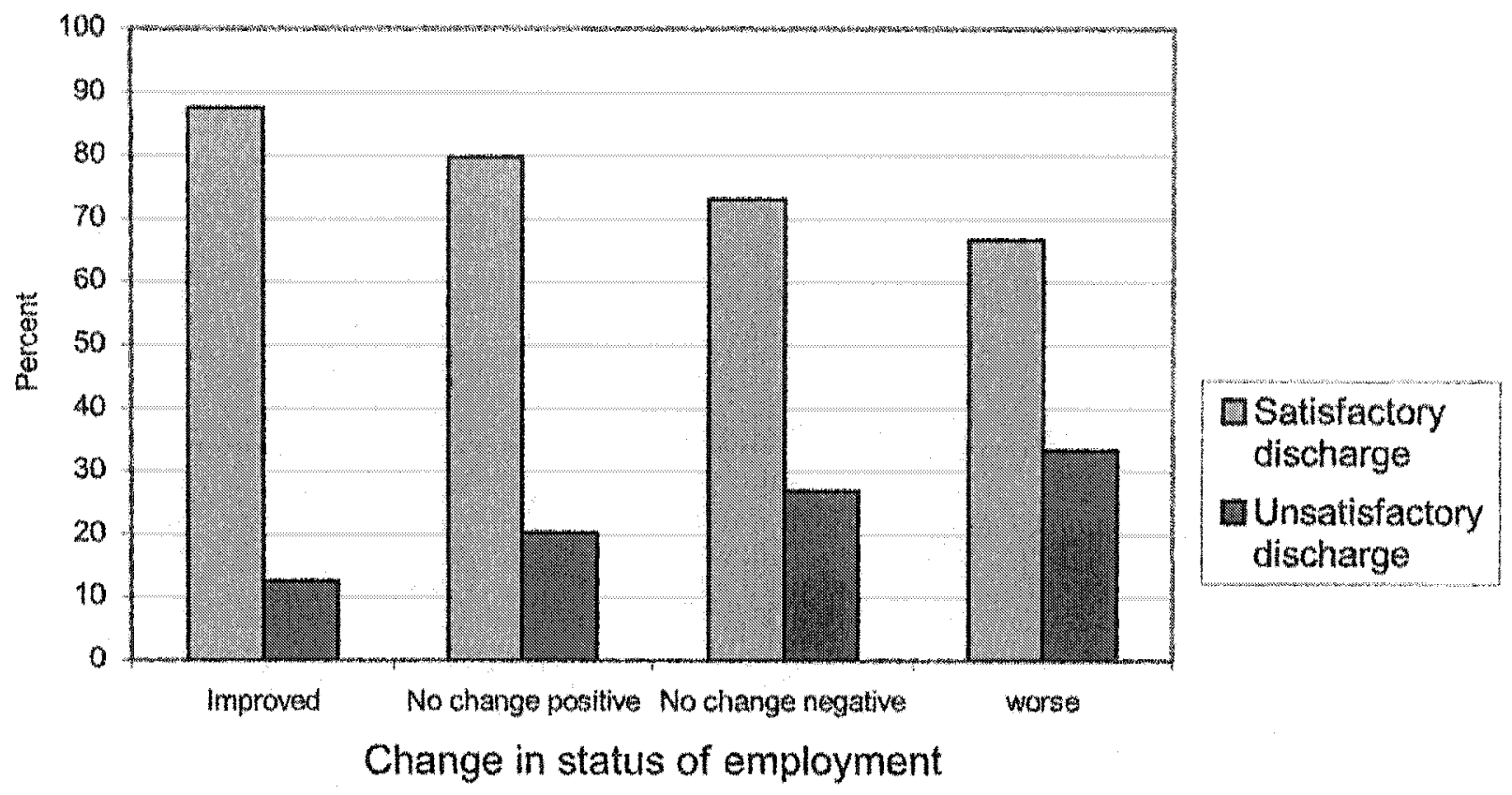


Table 4. Numbers and percentages in each category for status of employment and frequency of drug use.

\section{Employment status}

Frequency of

Continued to Continued to be

Drug use

Got ajob
be employed unemployed Lost job

Less use 132 221

$(78.1 \%)$

93

27

$(82 \%)$

$(75.6 \%)$

$(61.4 \%)$

Same use

$$
23
$$

$(14.3 \%)$

58

(20.5\%)

25

$(20.3 \%)$

15

More use

6

$(3.7 \%)$

4

$(1.4 \%)$

5
$(4.1 \%)$

$(34.1 \%)$

Total

161

$(100 \%)$

283
$(100 \%)$

$(4.1 \%) \quad(4.5 \%)$

2

$\begin{array}{rr}123 & 44 \\ (100 \%) & (100 \%)\end{array}$


Figure 3. Percentages for change in frequency of drug use by change in status of employment.

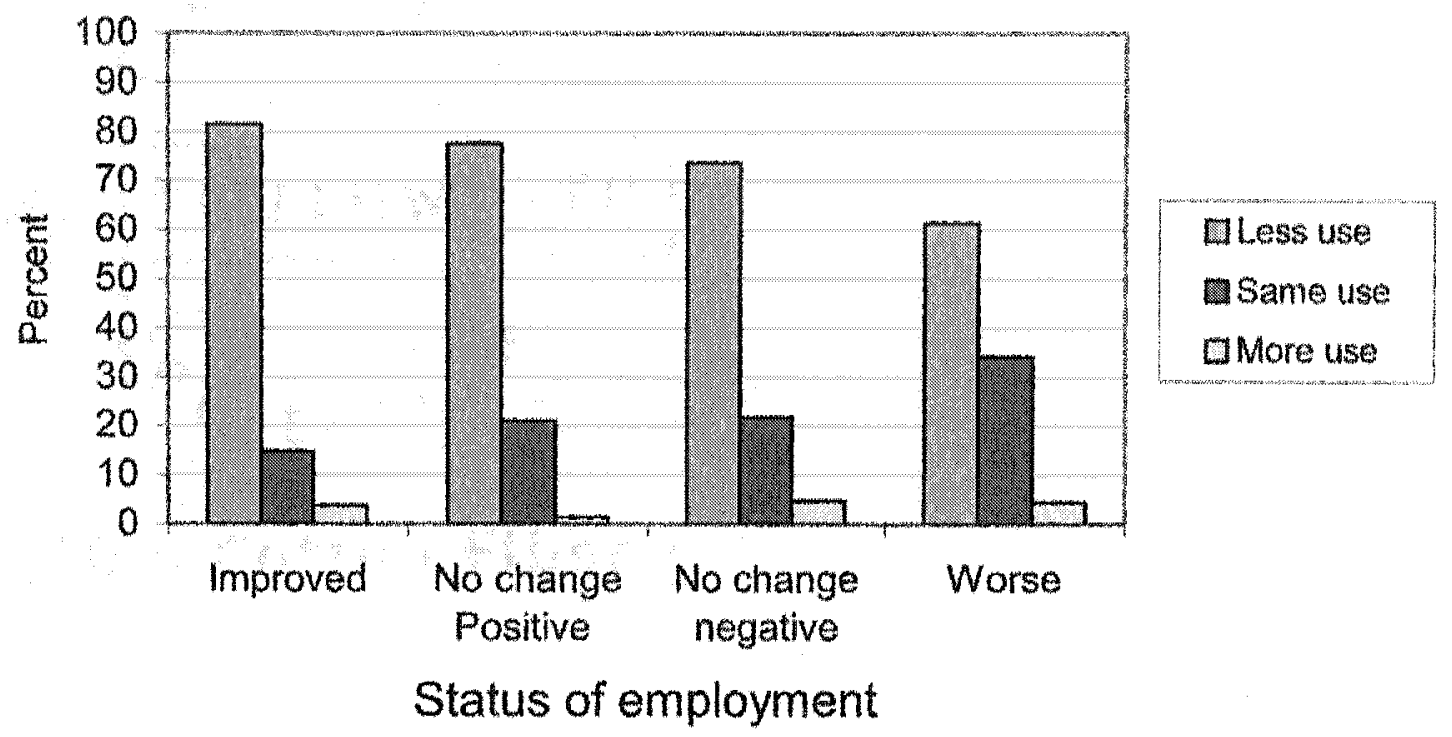




\section{Discussion}

This section will review the study's findings, their relationship to the suggested hypotheses, their implications, strengths and weaknesses, and directions for future research. Basically, the results of this study support the hypotheses. While they support the first hypothesis only partially, they do fully support the second hypothesis.

\section{Relationship Between Consumer Satisfaction and the Treatment Outcome}

The current findings suggest that while there is a significant positive effect of client satisfaction on discharge status, there was no such effect on frequency of drug use. These results support our hypothesis that clients who have high consumer satisfaction ratings at the end of the treatment episode will have better discharge status than clients with low consumer satisfaction ratings. But the results contradict with the hypothesis that clients who have high consumer satisfaction ratings at the end of the treatment episode will use drugs less frequently than those who have low consumer satisfaction ratings.

This finding is in line with other studies that found client satisfaction related to the treatment outcome measured in terms other than discharge status and frequency of drug use at discharge, but in terms of treatment retention (Chan et al., 1997), treatment gains in quality of life, symptoms, and level of functioning (Holcomb et al., 1997).

As mentioned carlier, client satisfaction is defined as the "clients" assessments regarding their perceptions of how well services matched their needs..." (Sanders, Trihn, Sheman, and Banks; 1998). Existence of a relationship between client satisfaction and discharge status, and no relationship between it and the frequency of drug use at 
discharge suggest that the two variables, discharge status and frequency of use at discharge do not behave exactly the same. This might be partially related to the tact that discharge status is determined by the counselor, according to the change that he saw in the clients attitudes and behaviors. While frequency of drug use is independent of what the counselor think, it is a more credible measure (based on urine tests) for the drug use behavior of the elient.

Client satisfaction is a measure of accountability, and an important factor of the program evaluation (Sorenson et al., 1979). As Sanders et al. (1998) assert any assessment of a drug treatment program will not be complete, unless it takes into account the client's perspective regarding the quality, use, and delivery of the services. Their input is very important in orler to improve the treatment program and the quality of the services.

The current results are consistent with the results of other client satisfaction studies that suggest that people are generally satisfied when provided with treatment (Nguyen et al., 1983), regardless of the treatment modality (Conners \& Franklin, 2000) and even when the treatment programs are not meeting their goals (Sanders, Tribn, Sherman \& Banks, 1998). When drug abuse clients find that someone is taking care of them, they are not alone facing their addiction problem, they are somewhat satisfied.

How might the use of the CSQ-8 affect the results? Although the use of the CSQ8 did not help us to identify aspects of the treatment that are improvement priorities, our findings do not contradict the notion that dimensional questionnaires can be very effective in identifying these aspects. This is basically due to the fact that the $\mathrm{CSO}-8$ is 
not dimensional, and it is mainly an indicator of the general satisfaction from the treatment. Furthermore, the use of open-ended questionnaires can provide more information about the quality of the treatment programs offered, and what should be changed. Obviously, the use of both qualitative and quantitative measures for client satisfaction can provide more understanding of the treatment components that affect satisfaction (Sanders et al., 1998).

In general, the client's satisfaction with the treatment determines how intrinsically committed the client is to the treatment, how ready is he to make the changes needed to quit the addiction, including changing his beliefs and attitudes toward the drug abuse, and getting ready to accept a new lifestyle.

\section{Relationship Between Status of Employment and Treatment Outcome}

Results regarding the effects of change in status of employment on treatment outcome support our hypothesis that clients, who get a job or those who continue to be employed during the treatment episode, will have better discharge status compared to clients who lost their jobs or those who continued to be unemployed, and that clients, who get a job or those who continue to be employed during the treatment episode, will use drugs less frequently, compared to clients who lost their jobs or those who continued to be unemployed.

These findings are consistent with findings by other previous studies (e.g. Hser, Hoffman, Grella \& Anglin; 2001). Sterling of al. (2001) in an interview 9 months after the clients were discharged, found that employed persons reported significantly fewer 
days of cocaine use in the month before follow-up than those not employed. Also, significantly smaller percentage of persons working gave urine samples that were cocaine positive than did those who were not working.

What is the basis of this relationship between employment status and treatment outcome? Employment functions as an indicator of treatment outcome; (Hermalin, Steer, Platt, Metzger \& Risk, 1990) particularly since it helps clients to integrate with the larger society, and allows for economic self-sufficiency. Furthermore, employment helps abstinent previous drug users to stay clean, especially since they invest most of their day hours at the work place, where they are not allowed to use drugs, and they are too busy fulfilling their job tasks from even thinking about using drugs. Employment activates their bodies and their minds, and gives them a lot of self-satisfaction and helps improve their well-being.

\section{Implications}

Implications for this finding include putting more emphasis during the treatment on employment, giving the clients vocational skills, and trying actively to get them employed. Here, the Therapeutic Workplace experience becomes very relevant, as a first job experience for the discharged clients after their addiction began to be a real problem. This can either be considered as part of their drug treatment, or adversely, it can be independent of the treatment plan, offered as an extra service for those who are interested and committed to a wotkplace environment.

Strengths and Weaknesses 
The results of this study acd to the body of knowledge in this field for two reasons. First, it sheds some light over the effects of change in status of etrployment on the success of the treatment, which can suggest changes in the tratment objectives. Second, the study focuses on outpationt clients who are underrepresented in the research of alcohol and drugs treatment.

This study has some limitations. First, as a study that one of its emphases was on client satisfaction, a major limitation is that clients who did not fill the Client Satisfaction Questionnaire (CSQ-8) were excluded from the study. This raises the question of why some clients have this questionnaire filled while others don't. How do these two groups (those who filled the $\operatorname{CSQ}-8$, and the others who did not) differ from each other on their satisfaction from treatment and on other variables? What would a follow-up on these clients suggest?

Another limitation is the vagueness of the definition of "treatment outcome." Especially in the field of alcohol and drug treatments, where relapse to drug use is very common, it is indistinctive when treatment outcome is good enough to be considered as satisfactory outcome (Zarkin, Dunlap, Jeremy, Bray, Wechsberg, 2002). In this study, we defined treatment outcome based on the counselor's decision of how satisfactory the client's discharge was. In addition, we added the frequency of drug use during the last month of treatment compared to the use a month before beginning with the treatment. This is a more credible measure for the success of the treatment since it is measured by urine tests, while discharge status is the decision of the counselor. Using both of them give us mote precise definition of treatment outcome. 
The generalizability of the current study is very limited especially since it addresses only clients at Santa Clara County, Califomia. So that results might be influenced by sampling or response bias. However, these results are certainly important for the Department of Drug and Alcohol at Santa Clara County. In addition, generally it adds to what we know in the area of both client satisfaction and employment status of drug and alcohol treatment clients.

Future Research

Future research is needed to further explore the effects of other dimensional client satisfaction questionnaires, especially those that include open-ended items that allow the client to express his/her thoughts regarding the treatment, and suggestions about how it should be improved. A study like this will help to explore the potential of client satisfaction in the process of drug and alcohol treatment. In addition to testing the relationship between client satisfaction and treatment outcome, such a study will belp to identify what factors in client satisfaction contribute to each and every aspect of treatment outcome. These relationships were not tested in the current study, especially due to the fact that the CSQ-8 is mainly an indicator of the general satisfaction from the treatment and does not address any of the client satisfaction dimensions. These dimensions are extremely important for reshaping treatments of drug and alcohol clients. 


\section{References}

American Psychiatric Association, Diagnostic and Statistical Marual of Mental Disorders, $4^{\text {th }} \mathrm{ed}$, Author, Washington, D.C., 1994.

Attkisson, C. C., Zwick, R. (1982), The client satisfaction questionnaire: Psychonetric properties and correlations with service utilization and psychotherapy outcome. Evaluation and Program Planning, 5, 233-237.

Attkisson, C. C., Greenfield, T. K. Client Satisfaction questionnaire-8 and Service Satisfaction Scale-30. In Maruish, M. E. (Ed.). The use of Pychological Testing for Treatment Planning and Outcome Assessment, 17, 402-420. Hillsdale: Lawrence Eribaum associates, 1994.

Attkisson, C. C., Greenfield, T. K. The client satisfaction questionnaire (CSQ) scales and the service satisfaction scale-30 (SSS-30). In Sender, L. I \& Dickey, B. (Eds.). Outcomes Assessment in Clinical Practice, 23, 120m127. Baltimore: Williams \& Wilkins, 1995.

Braunstein, W. B., Powell, B. J., McGowan, J. F. Thoreson, R.W. (1983). Employment factors in outpatient recovery of alcoholics: a multivariate study. Addiction Behavior, 8, 345-351.

Bray, J. W., Zarkin, G. A., Dennis, M. L. \& French, M. T. (2000). Symptoms of dependence, multiple substance use, and labor market outcomes. American Journal of Drug and Alcohol Abuse, 26, 77-95.

Catalano, R. F., Howard, M. O., Hawkins, J, D. and Wells, E. A. (1988). Relapse in addictions: Rates, Determinants, and Promising Relapse Strategies. Report No. 69, University of Washington, Seattle, WA.

Cemovsky, Z. Z., O'Reilly, R. L. \& Pennington, M. (1997). Sensation seeking scales and consumer satisfaction with substance abuse treatment program. Joumal of Clinical Psychology, 53, 779-784.

Chan, M., Sorenson, J. L., Guydish, J., Tajima, B. Acampora, A. (1997). Client satisfaction with drug abuse day treatment versus residential care. Journal of Drug Issues, 27, 367 377.

Conners, N. A.\& Franklin, K. K.(2000). Using focus groups to evaluate client satisfaction in an alcohol and drug treatment program. Joumal of Substance Abuse Treatment, $18 \times 313-320$. 
Donohue, B., Aciemo, R. \& Kogan, E. (1996). Relationship of depression with measures of social functioning in adult drug abusers. Addiction Behavior, $21,211-216$.

Greentield, T. K., Atkisson, C. C. (1989). Steps toward a multifactorial satisfaction scale for primary care and mental health services. Evaluation and Program Planning, $12,271-278$

Greenfield, T. K., Beigel, A., Torre, C. A pilot study of consumerr satisfaction with mental health programs in the county of Los Angeles in 1995. September, 1995.

Harrisson, P. A., Beebe, T. J., Fulkerson, J. A. \& Torgerud, C. R. (1996). The development of patient profiles for Minnesota's treatment outcomes monitoring system. Addiction, 91, 687-699.

Hermalin, J.; Steer, R.; Platt, J.; Metzger, D. (1990). Risk characteristics associated with chronic unemployment in methadone clients. Drug and Alcohol Dependence, 26, 117-125.

Hoffman, J. A., Caudill, B. D., Koman, J. J., Luckey, J. W., Flynn, P. M., Mayo, D. W. (1996). Psychosocial Treatments for Cocaine Abuse: 12-Month Treatment Outcomes. Journal of Substance Abuse Treatment, 13, 3-11.

Holcomb, W. R., Parker, J.C., Leong, G. B. (1997). Outcomes of inpatients treated on a VA psychiatric unit and a substance abuse treatment unit. Psychiatric Services, 48, 699-704.

Howard, D. L. (2003). Are treatment goals of culturally competent outpatient substance abuse treatment units congruent with their client profile? Journal of Substance Abuse Treatment, 24, 103-113.

Hser, Y., Hoffman, V., Grella, C. E.\& Anglin, M. D. (2001). A 33 year follow-up of narcotic addicts. Archives of general Psychiatry, 58, 503-508.

Hser, Y., Grella, C. E., Hubbard, R. L., Hsieh, S., Fletcher, B. W., Brown, B. S., Anglin, M. D. (2001). An evaluation of drug treatments for adolescents in 4 US cities. Archives of General Psychiatry, 58,689-703.*

Hser, Y., Polinsky, M. L., Maglione, M., \& Anglin, M. D. (1999). Maching clients' needs with drug treatment services. Journal of Substance Abuse Treatment, 16, 299-305.

Laudet, A. (2002). Interests in and obstacles to pursuing work among unemployed dually diagnosed individuals. Substance Use and Misuse, 37, 145-170.

Luchansky, B., Brown, M. Longhi, D, Stark, K. \&. Krupski, A. (2000). Chemical 
dependency treattnent and employment outcomes; results from the "ADATSA' program in Washington State. Drug and Alcohol Dependence, 60, 151-159.

MeLellan, A. T., Hunkeler, E., 1998. Patient Satisfaction and outcomes in alcohol and drug abuse treatment. Psychiatric Services, 49, 573-575.

Metzger, D. S. Platt, J, J., (1990), Solving vocational problems for addicts in treatment. In : Platt, J., Kaplan, C. MoKim, P., Editors, 1990. The Effectiveness of Drug Abuse Treatment: Dutch and American Perspectives, Krieger Publishing, Malabar, FL, pp.101-111.

Moggi, F., Ouimette, P. C., Finney, J. W., Moos, R. H. (1999). Effectiveness of treatment for substance abuse and dependence for dual diagnosis patients: a model of treatment factors associated with one year outcomes. Journal of Studies on Alcohol, 60, 856 875 .

McMahon, R., Kouzekanani, K., Malow, R. M. (1999). A comparative study of cocaine treatment completers and dropouts. Journal of Substance Abuse Treatment, 16, $17-22$.

Neff, J. A., Zule, W. (2002). Predictive validity of a measure of treatment readiness for out of treatment drug users: enhancing prediction beyond demographic and drug history variables. American Journal of Drug and Alcohol Abuse, 28, 147-170.

Nguyen, T. D. Attkisson, C. C., Stegner, B. L. (1983). Assessment of patient satisfaction: Development and refinement of service evaluation questionnaire. Evaluation and Program Planning, 6, 299-314.

Primm, A. B., Gomez, M. B., Tzolova-Iontchev, I., Perry, W., Vu, H. T., \& Crum, R. M. (2000). Severely mentally ill patients with and without substance use disorders: Characteristics associated with treatment attrition. Community Mental Health Joumal, 36, 235-246.

Rapp, R. C., Siegal, H. A., Li, L., Saha, P. (1998). Predicting postprimary treatment services and drug use outcome: a multivariate analysis. American Joumal of Drug and Alcohol Abuse, 24, 603-613.

Roberts, R. E., Attkisson, C. C. (1983). Assessing client satisfaction among Hispanies. Evaluation and Program Planning, 6, 401-413.

Roberts, R. E., Attkisson, C. C., Mendias, R. M. (1984). Assessing the client satisfaction questionnaire in English and Spanish. Hispanic Journal of Behavioral Sciences, 6 , 385-395. 
Round-Bryant, J. L., Kristiansen, P.L. \& Hubbard, R. L. (1999). Drug abuse treatment outcome study of adolescents: a comparison of client characteristics and pretreatment behaviors in three treatment modalities. American Joumal for Drug and Alcohol Abuse, 25, 573-591.

Sanders, L. M., Trinh, C., Sherrman, B. R., Banks, S. M.(1998). Assessment of client satisfaction in a peer counseling substance abuse treatment program for pregnant and postpartum women. Evaluation and Programming Planning, 21, 287-296.

Silverman, K., Svikis, D., Wong, C., Hampton, J., Stitzer, M. L. \& Bigelow, G. (2002). A reinforcement-based therapeutic workplace for the treatment of drug abuse: Three-year abstinence outcomes. Experimental and Clinical Psychopharmacology, 10, 228-240.

Silverman, K., Svikis, D., Robles, E., Stitzer, M. L., Bigelow, G. E. (2001). A reinforcement-based Therapeutic Workplace for the treatment of drug abuse: Sixmonth abstinence outcomes. Experimental and Clinical Psychopharmachology, 9, $14-23$.

Simpson, D. D. (1981). Treatment for drug abuse: Follow-up outcomes and length of time spent. Archives of General Psychiatry, 38, 875-880.

Smith, B. D. \& Marsh, J. C. (2002). Client-service matching in substance abuse treatment for women with children. Joumal of Substance Abuse Treatment, 22, 161-168.

Sorenson, J. L., Kantor, L., Margolis, R. B., Galanco, J. (1979). The extent, nature and utility of evaluating consumer satisfaction in community mental health centers. American Journal of Community Psychology, 7, 329-337.

Sterling, R. C., Gottheil, E., Glassman, S. D., Weinstein, S. P., Serota, R. D. \& Lundy, A. (2001). Correlates of employment: A cohort study. American Journal of Drug and Alcohol Abuse, 27, 137.

Sung-Yeon, K., Delion, (.. (1993). Correlates of drug injection behaviors among methadone outpatient. American Journal of Drug and Alcohol Abuse, 19, 107 112.

Weisner, C., Makgger, H., Tam, T., Schmidt, L. (2002). Who goes to alcohol and drug treatment? understanding utilization within the context of insurance. Journal of studies on Alcohol, $63,673 m 682$.

Williams, B., (1994). Patient satisfaction: a valid concept?. Social Science and Medicine, $38,508-516$. 
Zarkin, G.A., Dunlap, L.J., Bray, J.W.\& Wechsberg, W. M. (2002). The effect of treatment completion and length of stay on employment and crime in outpatient drug-free treatment. Journal of Substance Abuse Treatment, 23, 261-271. 
Appendix A

Client Satisfaction Questionnaire -8 


\section{CLIENT SATISFACTION QUESTIONNAIRE}

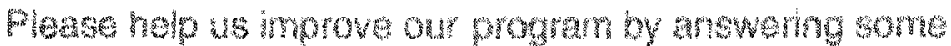
questions abouthe sarvoss you have recenger. We ara

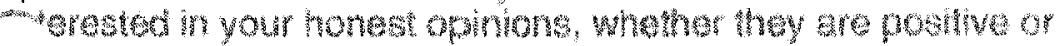

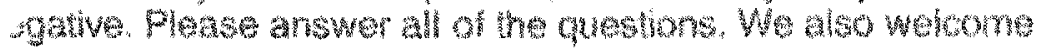
your comments and suggestons.

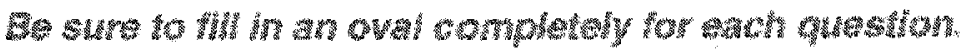

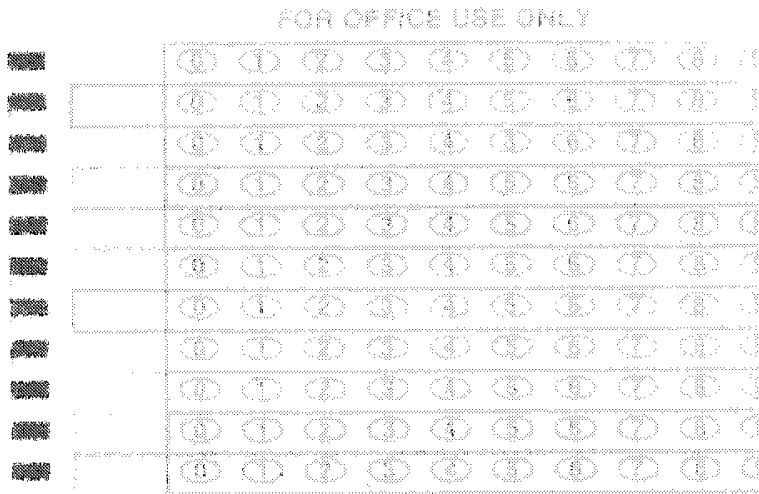

1. How would you rate the gually of service you have received?

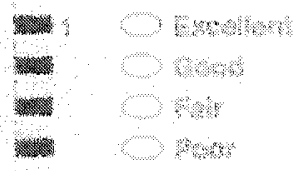

2. Did you get he knd of serves you wanted?

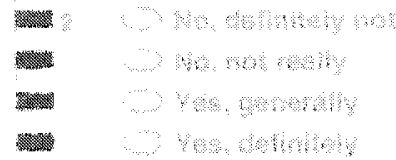

2. To whet axtent has our wortam met your noeds?

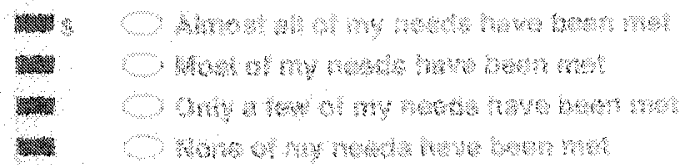

4. If a mend ware in need of smilar hel, woth you recommend our programio him ot her?

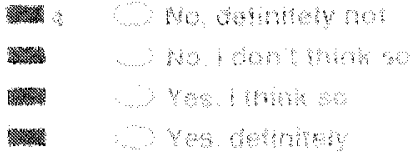

5. How satuthed are you with the amoun of hatp you have reched?

rox

,

How

h

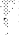

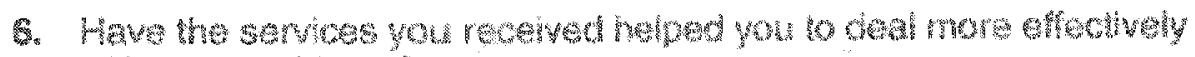
with your problems?

PLESE TUAN THS CAMO OVER FOA MORE OUESTONS
Whan wawhe

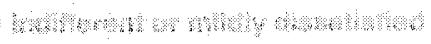

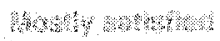

War manotrot

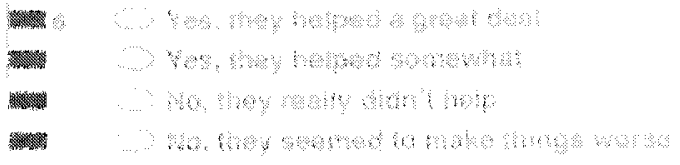

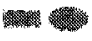

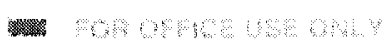


7. In an overal, general sense, how satisled are you with the service you have received?

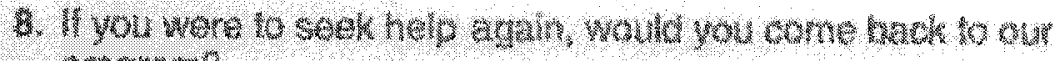
program?

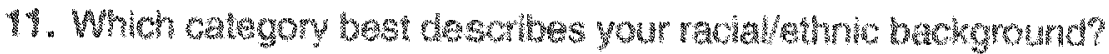

9. Mow old ara you?

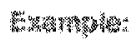

簿

$\left|\begin{array}{c}1 \\ 13 \\ 1\end{array}\right|$

s)

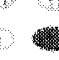

as

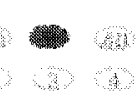

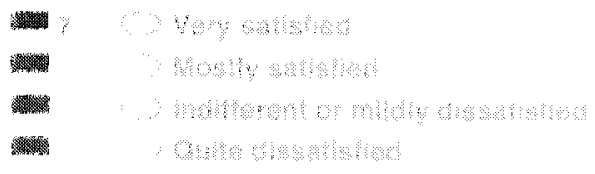

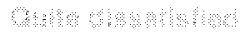

\%

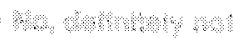

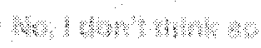

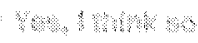

the wrothras

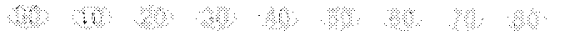

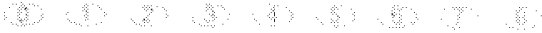

10. Ars you mate or tarnision?

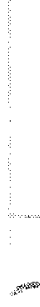

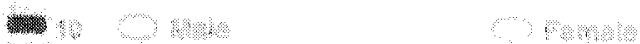

\begin{tabular}{|c|c|}
\hline 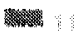 & 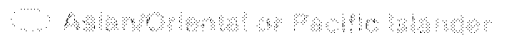 \\
\hline 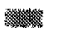 & 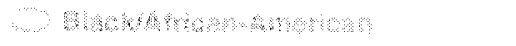 \\
\hline 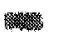 & 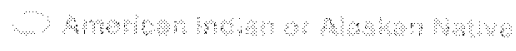 \\
\hline (6) & 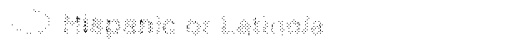 \\
\hline 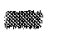 & 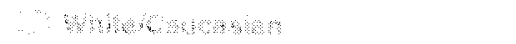 \\
\hline 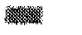 & $\therefore$ no: \\
\hline
\end{tabular}

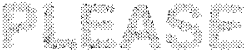

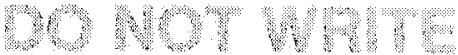

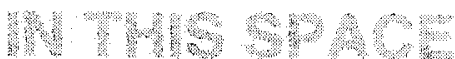

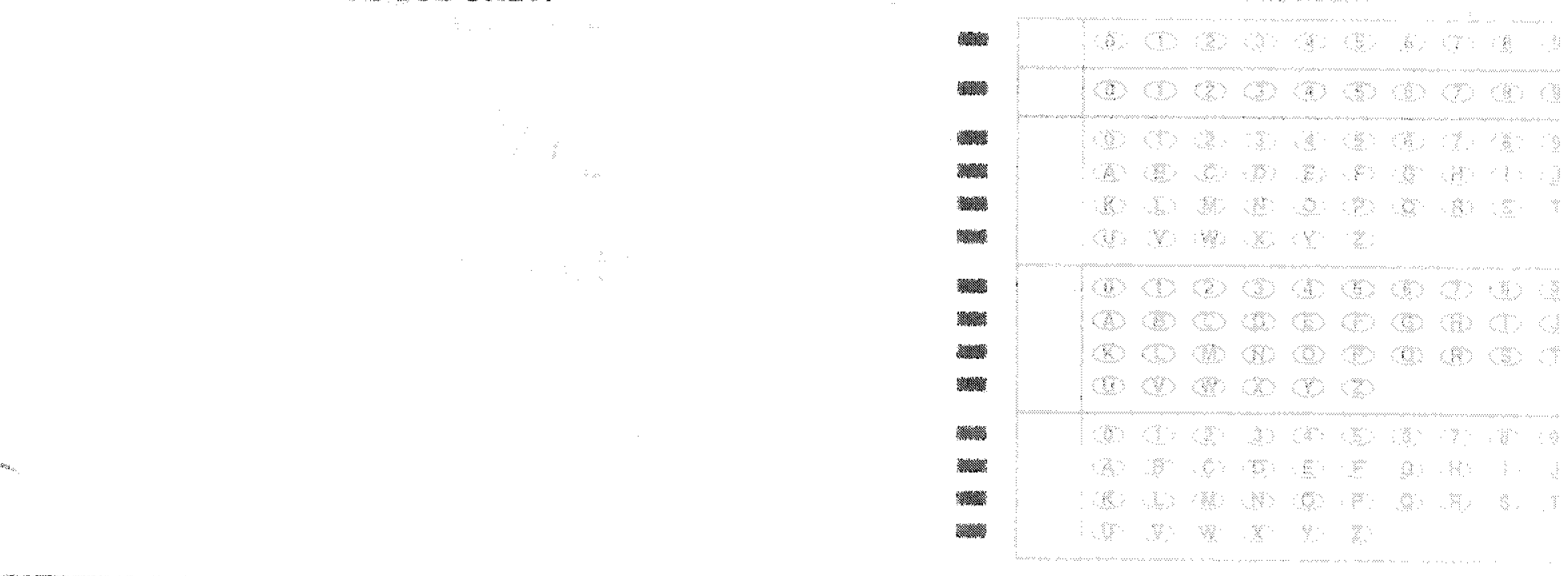


Appendix B

Human Subjects wIRB Approval 


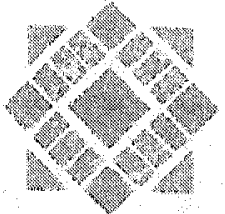

SanJosé State

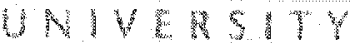

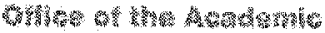

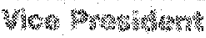

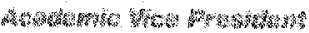
Grothos

wathoriton swate

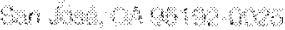

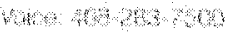

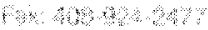

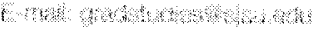

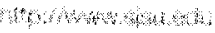

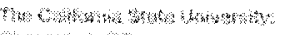

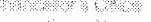

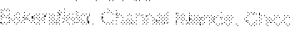

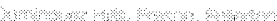

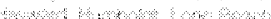
c. trice (2) w w a.

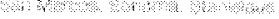

To: Kula Nasserwarkwi 6824 Marvin Avones

Prow: Pann staduk Mewark CA 94560

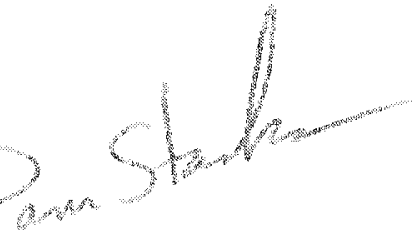

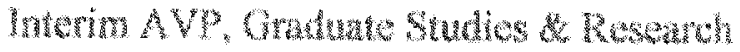

Date: November 16,2003

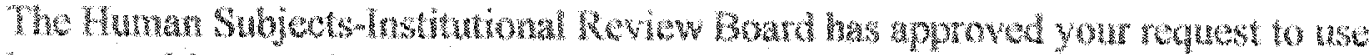
human stojegts in the staty encitiox.

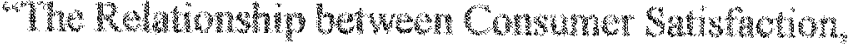

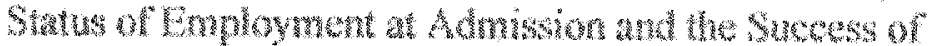

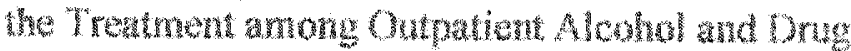 Adicted Chents."}

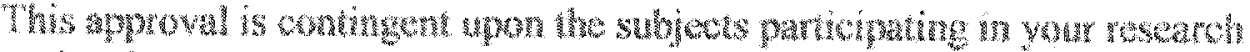
project baing appopriately protected trom risk. This induhes the protection whe

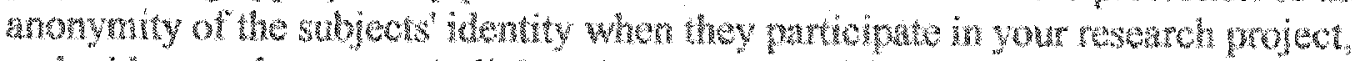
ard with regyud to any and all data that may be collected from the subicots. The

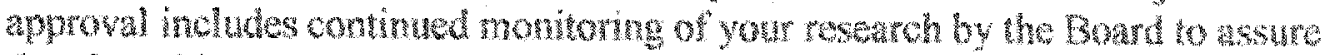
that the subjects are being adequately whd propery protedted trom such rises. If at

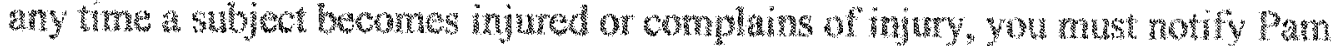

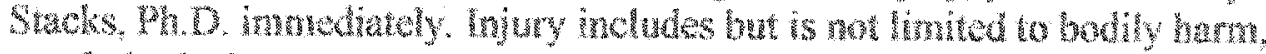
psychotogical wawn, and releaso of potwntaly domging persona infomation.

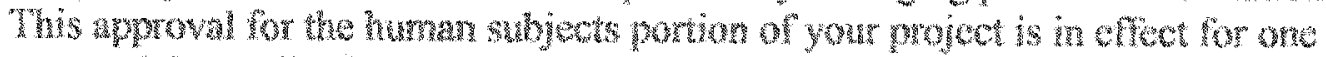
year and data collectom beyond November 16,2004 requires an oxtension requess?t.

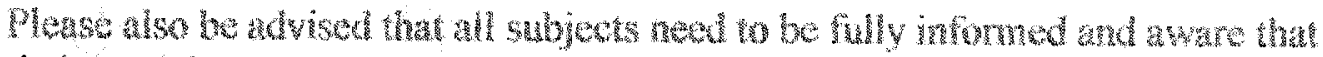

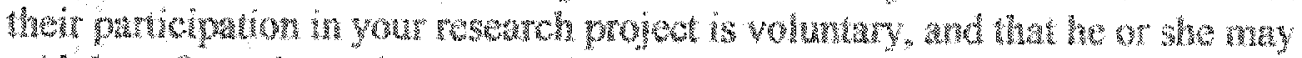

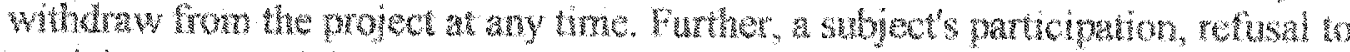

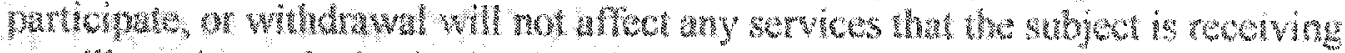

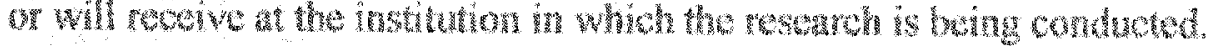

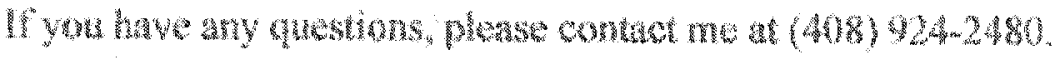

ce Dr. howath Townusa 